Supplement of

\title{
The three-dimensional life cycles of potential vorticity cutoffs: a global and selected regional climatologies in ERA-Interim (1979-2018)
}

Raphael Portmann et al.

Correspondence to: Raphael Portmann (raphael.portmann@env.ethz.ch)

The copyright of individual parts of the supplement might differ from the article licence. 


\section{S1. Climatological frequencies of the three cutoff types}
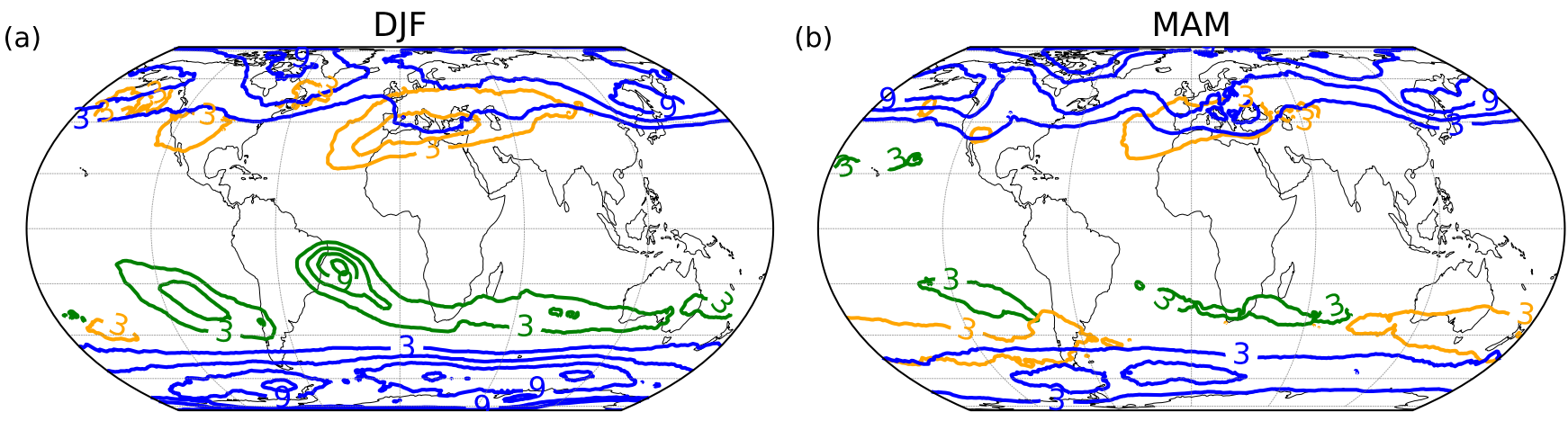

(c)

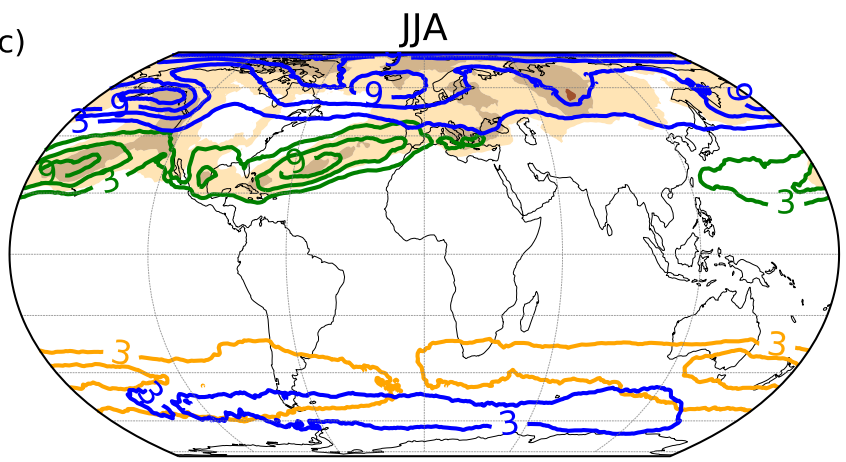

(d)

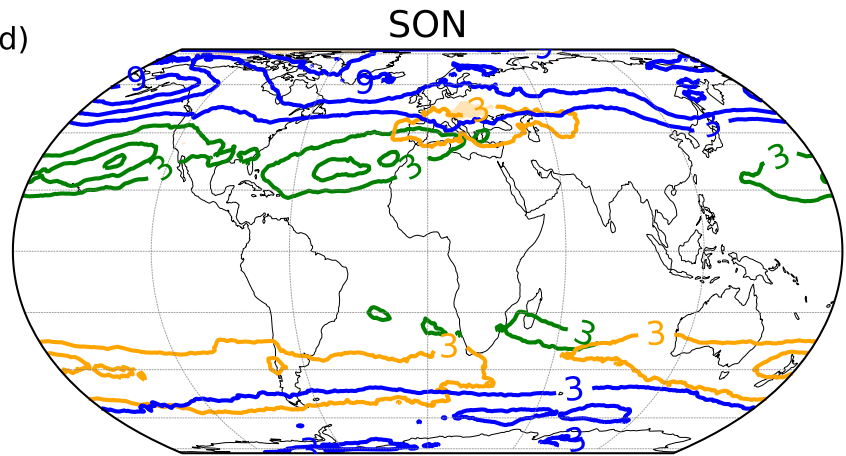

11

Figure S 1. Seasonally averaged frequencies of PV cutoffs of types I (green contours, every $3 \%$ ), II (orange contours), and III (blue contours) and the PV cutoffs that could not be classified (shading, in \%) for (a) DJF, (b) MAM, (a) JJA, and (b) SON. 


\section{S2. Details of the selected PV cutoff genesis regions}

10 Table $\mathrm{S} 1$ provides an overview of the geographical boundaries of the selected regions and the number of identified tracks with PV cutoff genesis in this region.

Table S 1. Details of the selected PV cutoff genesis regions in DJF and JJA

\begin{tabular}{|c|c|c|c|}
\hline genesis region & longitudes & latitudes & number of tracks \\
\hline \multicolumn{4}{|l|}{ DJF } \\
\hline California & $105-130^{\circ} \mathrm{W}$ & $25-45^{\circ} \mathrm{N}$ & 688 \\
\hline Nordic Seas & $20^{\circ} \mathrm{W}-15^{\circ} \mathrm{E}$ & $55-75^{\circ} \mathrm{N}$ & 808 \\
\hline Mediterranean & $0-30^{\circ} \mathrm{E}$ & $35-48^{\circ} \mathrm{N}$ & 729 \\
\hline eastern South Pacific & $70-90^{\circ} \mathrm{E}$ & $20-40^{\circ} \mathrm{S}$ & 406 \\
\hline South Africa & $0-25^{\circ} \mathrm{E}$ & $20-40^{\circ} \mathrm{S}$ & 491 \\
\hline Antarctica & $55-105^{\circ} \mathrm{E}$ & $50-65^{\circ} \mathrm{S}$ & 832 \\
\hline \multicolumn{4}{|l|}{ JJA } \\
\hline central subtropical N. Atlantic & $30-60^{\circ} \mathrm{W}$ & $20-35^{\circ} \mathrm{N}$ & 691 \\
\hline eastern subtropical N. Atlantic & $5-25^{\circ} \mathrm{W}$ & $25-40^{\circ} \mathrm{N}$ & 477 \\
\hline Mediterranean & $0-30^{\circ} \mathrm{E}$ & $35-48^{\circ} \mathrm{N}$ & 891 \\
\hline Hudson Bay & $70-115^{\circ} \mathrm{W}$ & $50-70^{\circ} \mathrm{N}$ & 898 \\
\hline Baltic Sea & $0-30^{\circ} \mathrm{E}$ & $50-65^{\circ} \mathrm{N}$ & 569 \\
\hline Australia & $105-140^{\circ} \mathrm{E}$ & $32-52^{\circ} \mathrm{S}$ & 969 \\
\hline
\end{tabular}




\section{S3. Example cases}

The following Figs. S2, S3, and S4 illustrate the application of the tracking method and at the same time provide examples for each of the three proposed life cycle types.

Figure S2 shows PV cutoff genesis over the central subtropical North Atlantic in JJA (Type I. anticyclonic). The PV cutoff forms at 18 UTC 18 Jun 2000 from a westward extending PV streamer equatorward of the jet stream and a large ridge. It then remains relatively stationary, slightly grows on $340 \mathrm{~K}$, decays diabatically on $335 \mathrm{~K}$ at 18 UTC 19 Jun 2000 and merges with a pre-existing PV cutoff at 00 UTC 20 Jun 2000. It reappears on $335 \mathrm{~K}$ and appears for the first time on $345 \mathrm{~K}$ at 12 UTC 20 Jun 2000. It is then reabsorbed first on $345 \mathrm{~K}$ and later, from 00 UTC to 06 UTC 22 Jun 2000, on $340 \mathrm{~K}$. On $335 \mathrm{~K}$ it shrinks and finally decays at 06 UTC 22 Jun 2000. During the whole life cycle it is not linked to a surface cyclone.

Figure S3 shows PV cutoff genesis over Australia in JJA (Type II, between-jets). The PV cutoff forms at 00 UTC 25 Aug 2001 from the cyclonic break-up of a anticyclonically tilted PV streamer equatorward of the polar jet stream and poleward of a strong subtropical jet. Alread $12 \mathrm{~h}$ after PV cutoff genesis, a surface cyclone forms at the PV cutoff's eastern flank, which subsequently intensifies. As the cyclone intensifies the PV cutoff shrinks at all levels and decays diabatically at 295 and $300 \mathrm{~K}$. Surface cyclone and PV cutoff then form an equivalent barotropic system around 12 UTC 27 Aug 2001. At the same time, the PV cutoff detaches from the stratospheric reservoir on $315 \mathrm{~K}$ and is reabsorbed again only $12 \mathrm{~h}$ later. The PV cutoff finally decays diabatically on $305 \mathrm{~K}$ and $310 \mathrm{~K}$.

Figure S4 shows PV cutoff genesis over the western North Atlantic in DJF (Type III, cyclonic). It forms at 06 UTC 06 Jan 1989 on 290-300 K from cyclonic wave breaking equatorward of a large, pre-existing surface cyclone south of Greenland and poleward of the jet stream. Subsequently it moves rapidly northeastward, appears shortly on $305 \mathrm{~K}$ and is subsequently reabsorbed again on that isentrope. At the same time, it decays diabatically on $290 \mathrm{~K}$ and shrinks substantially on $295 \mathrm{~K}$. At 00 UTC 07 Jan 1989 cyclogenesis occurs ahead of the PV cutoff west of Iceland. The surface cyclone remains in the vicinity of the PV cutoff for about one day and then moves eastward while the PV cutoff remains quasi-stationary between Greenland and Iceland where it is finally reabsorbed at 12 UTC 09 Jan 1989. During the quasi-stationary period, the PV cutoff decays and reappears again on $295 \mathrm{~K}$. 


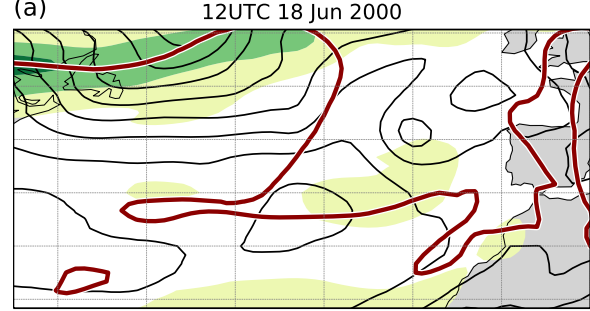

18UTC 18 Jun 2000

(c)

OOUTC 19 Jun 2000

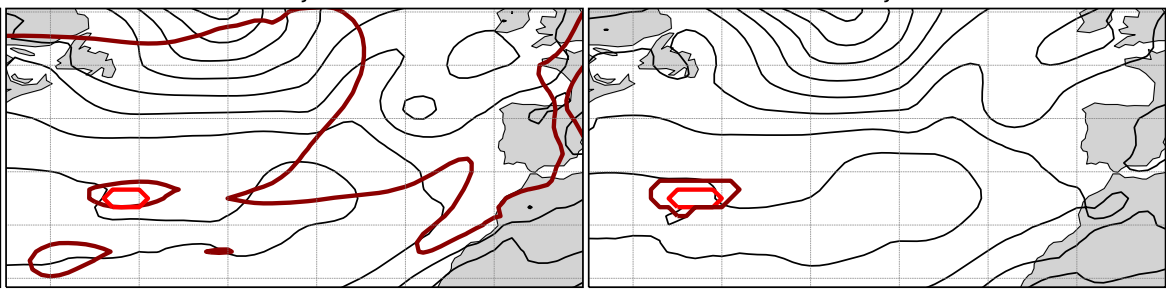

(d)

(e) $\quad$ 12UTC 19 Jun 2000

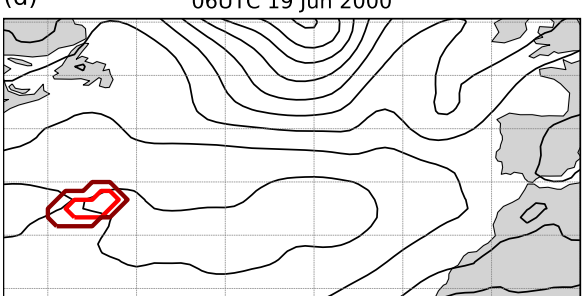

(f)

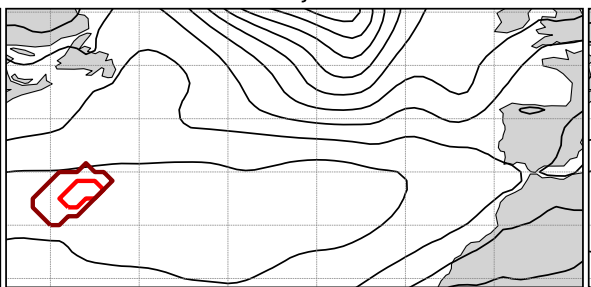

(f) $\quad$ 18UTC 19 Jun 2000

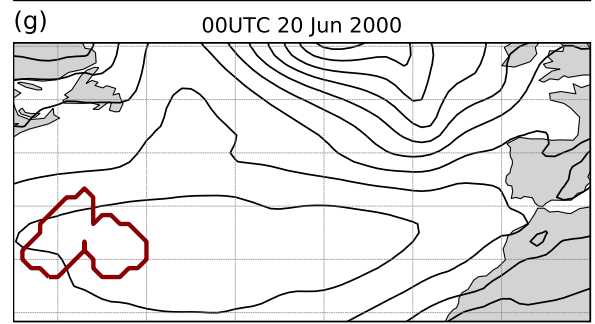

(h) $\quad$ 06UTC 20 Jun 2000

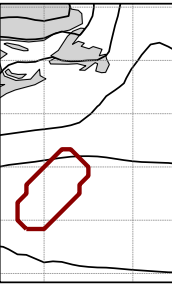

n
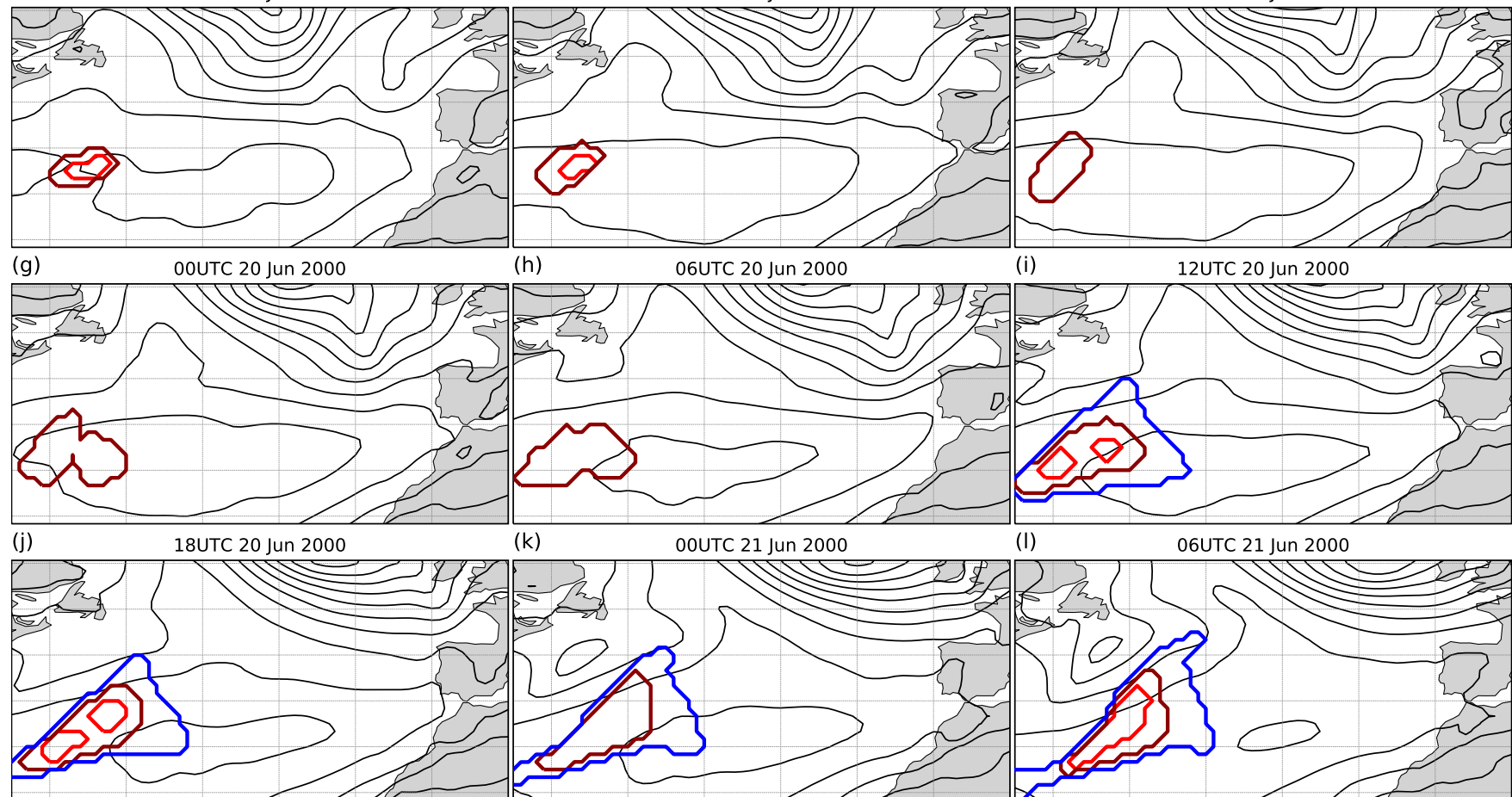

(I) $\quad$ 06UTC 21 Jun 2000

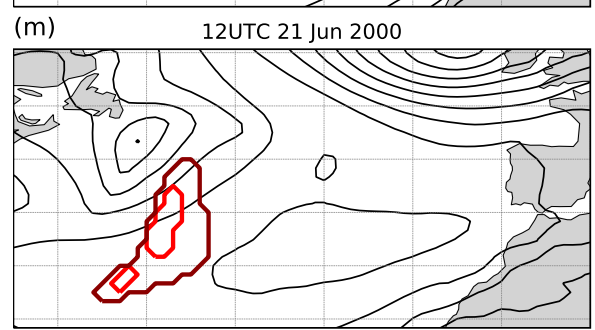

(n)

18UTC 21 Jun 2000
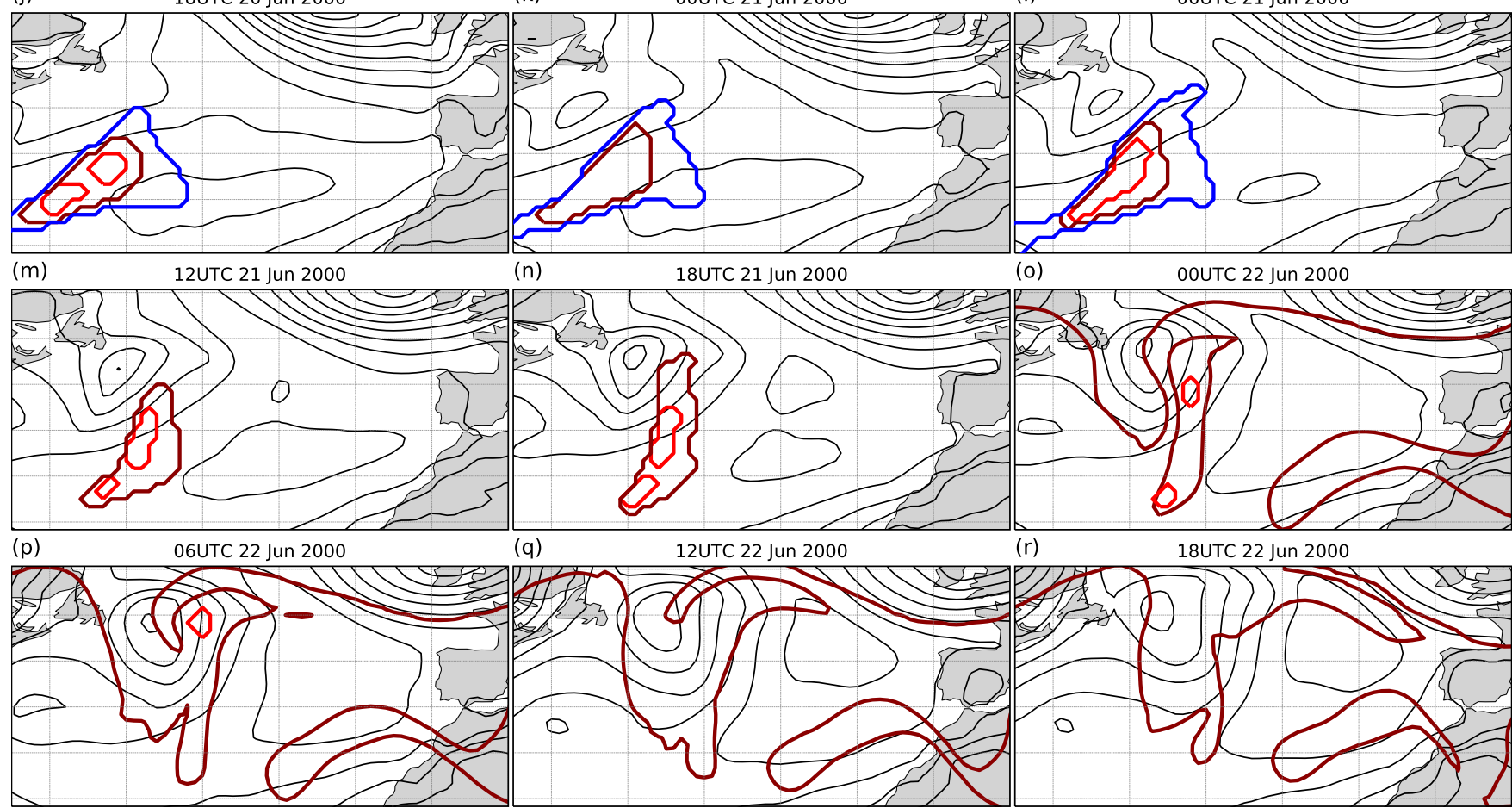

(q) 12UTC 22 Jun 2000
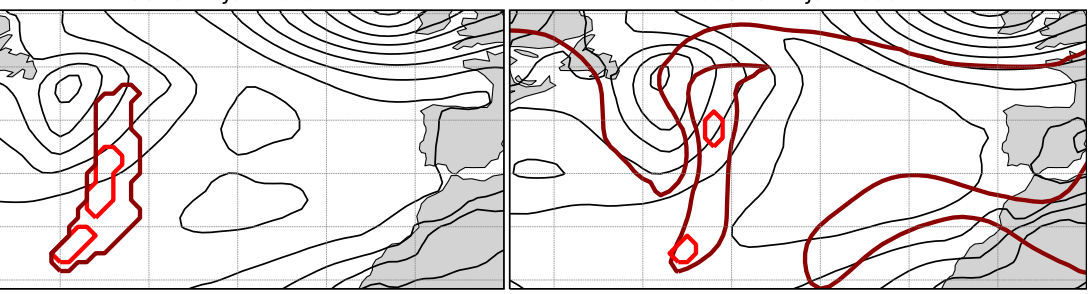

(r)

18UTC 22 Jun 2000
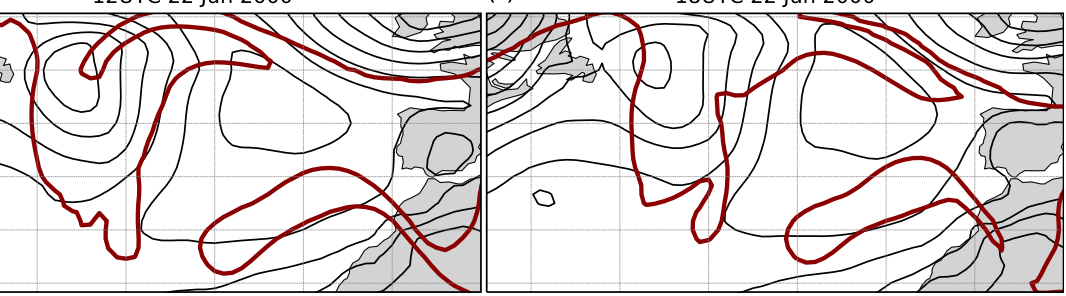

Figure S 2. Case study of a PV cutoff forming over the central subtropical North Atlantic (Type I, anticyclonic). Shown are the 2 PVU isoline on $340 \mathrm{~K}$ (brown) in panels a,b and o-r and masks of the identified PV cutoff at $335 \mathrm{~K}$ (red), $340 \mathrm{~K}$ (brown), and $345 \mathrm{~K}$ (blue), sea level pressure (black), and, for panel (a), wind speed at $250 \mathrm{hPa}$ (green shading, 20,40,60 $\mathrm{m} \mathrm{s}^{-1}$ ). 
(c)

06UTC 25 Aug 2001
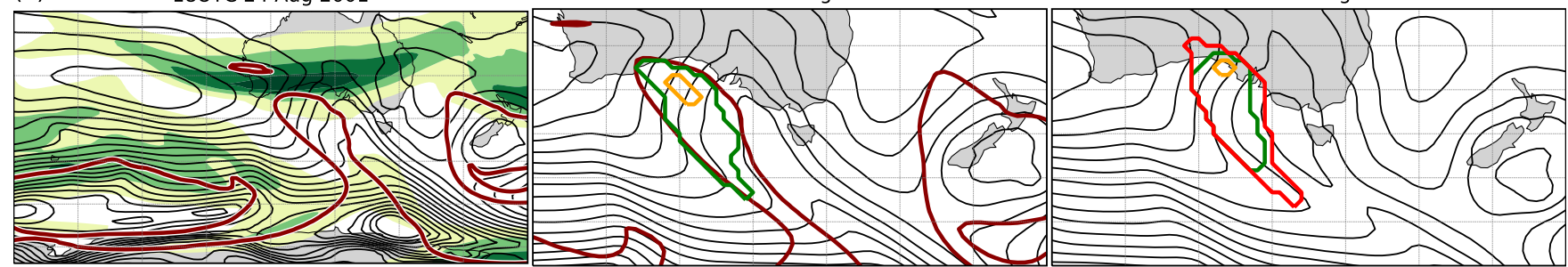

(d)

12UTC 25 Aug 2001

(e)

18UTC 25 Aug 2001

(f)

OOUTC 26 Aug 2001
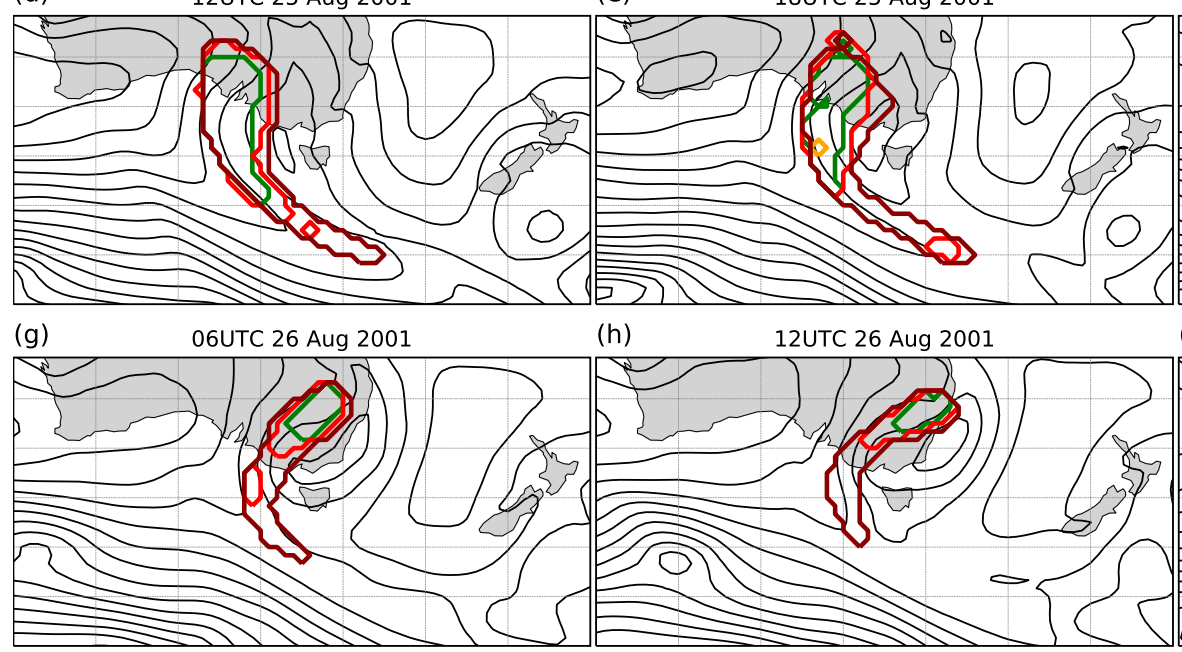

(h) 12UTC 26 Aug 2001
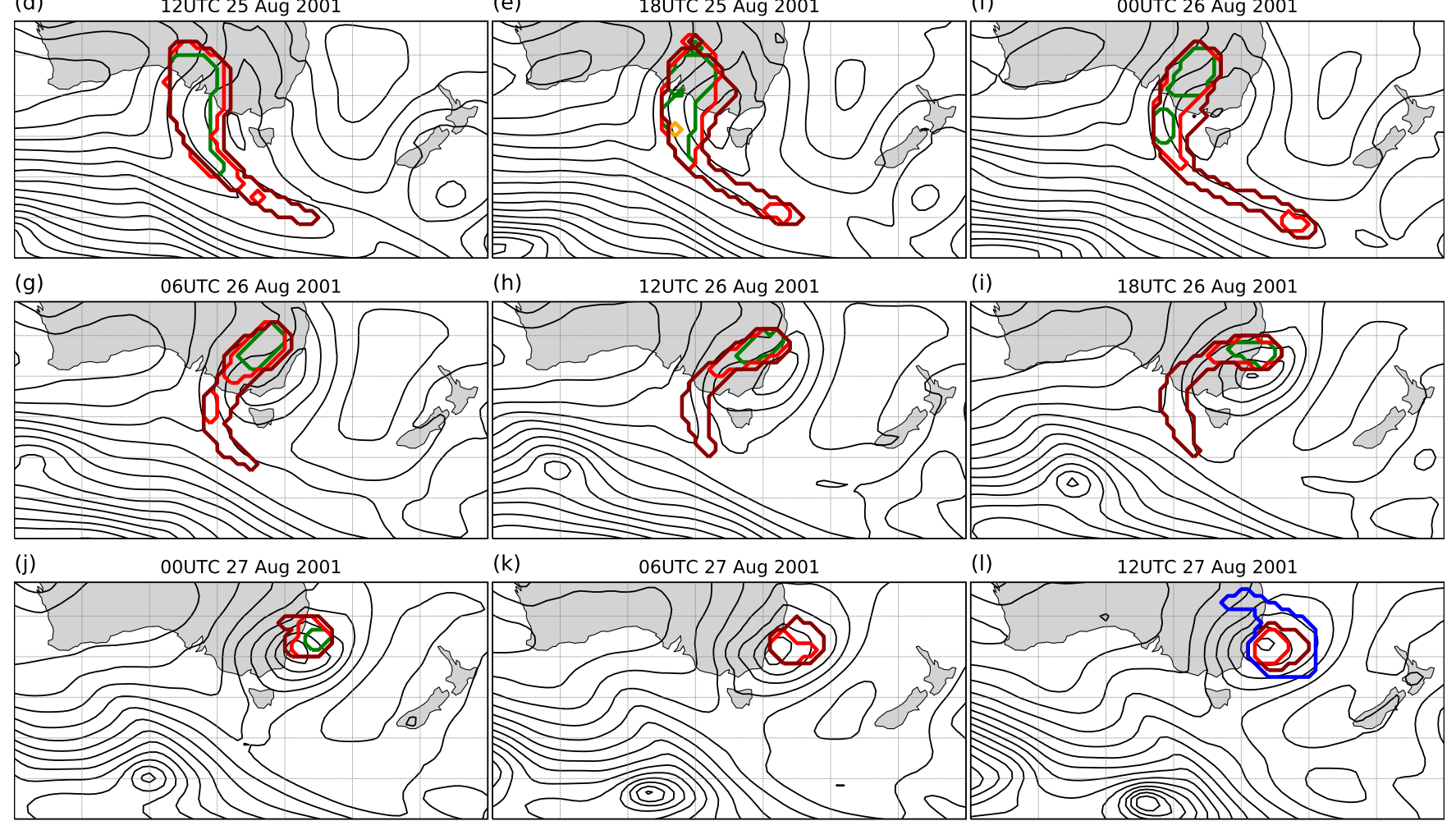

(k) 06UTC 27 Aug 2001

(I)

12UTC 27 Aug 2001
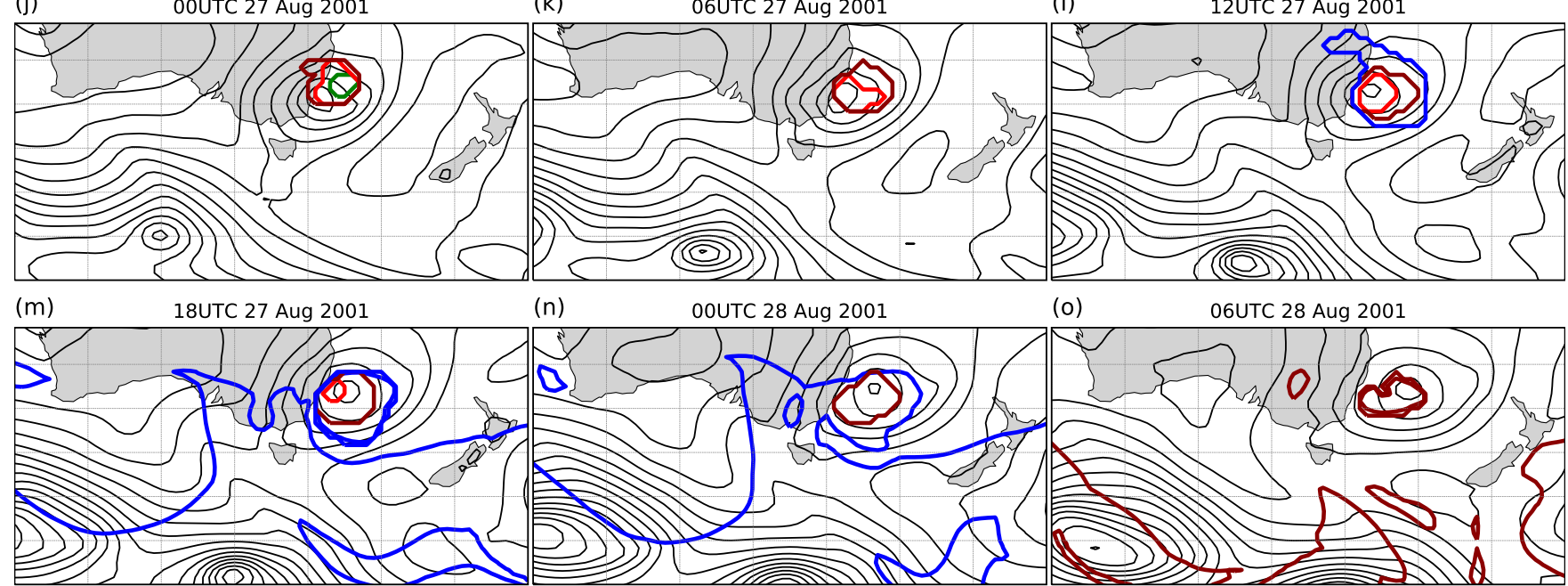

(n) $\quad$ OOUTC 28 Aug 2001

(o)

06UTC 28 Aug 2001

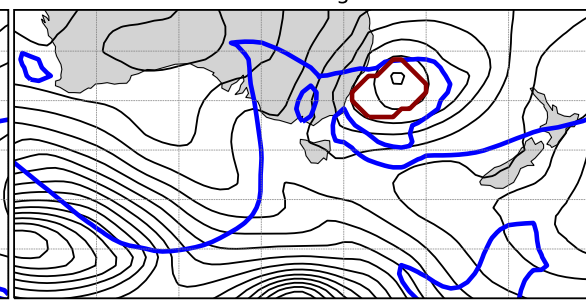

(p)

(q)
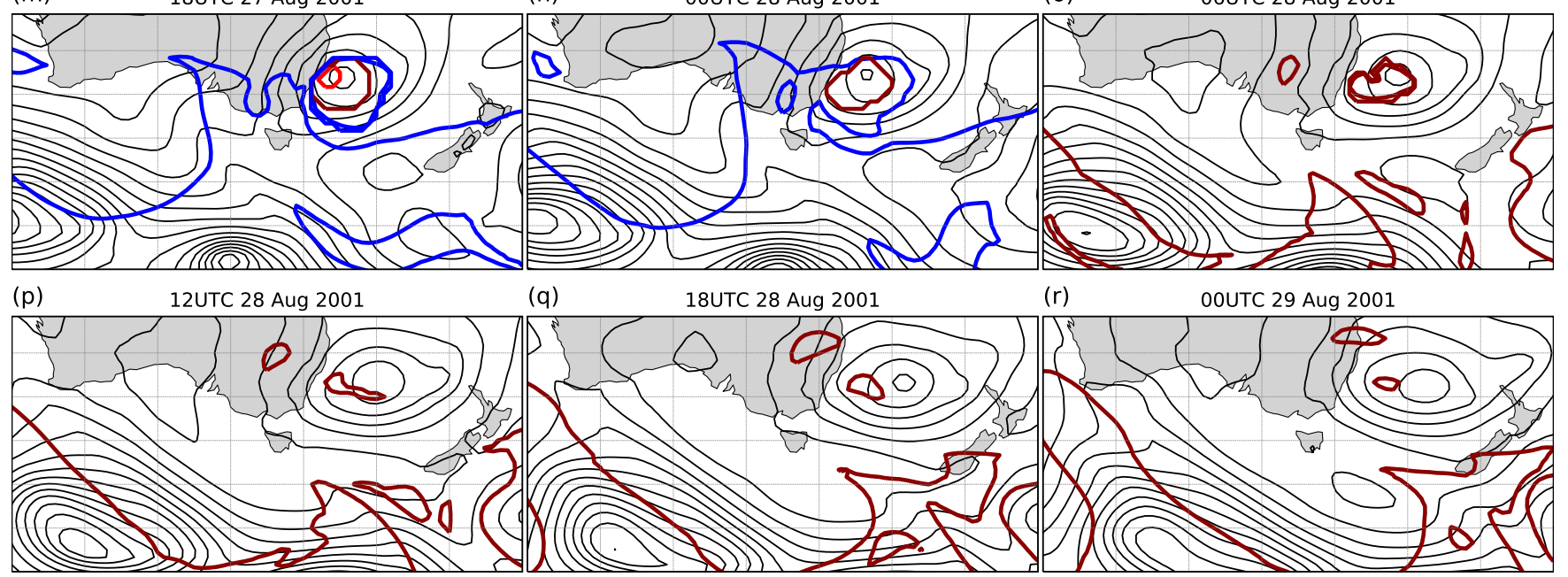

(r)

OOUTC 29 Aug 2001

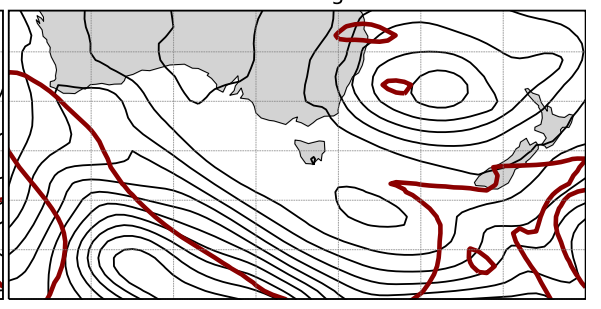

Figure S 3. Case study of a PV cutoff forming over Australia (Type II, between-jets). Shown are the 2 PVU isoline on (a,b,o-r) $310 \mathrm{~K}$ (brown) and on (m,n) $315 \mathrm{~K}$ and masks of the identified PV cutoff at $290 \mathrm{~K}$ (orange) and $300 \mathrm{~K}$ (green), $305 \mathrm{~K}$ (red), $310 \mathrm{~K}$ (brown), and $315 \mathrm{~K}$ (blue), sea level pressure (black), and, for panel (a), wind speed at $250 \mathrm{hPa}$ (green shading, 20,40,60,80 $\mathrm{m} \mathrm{s}^{-1}$ ). 

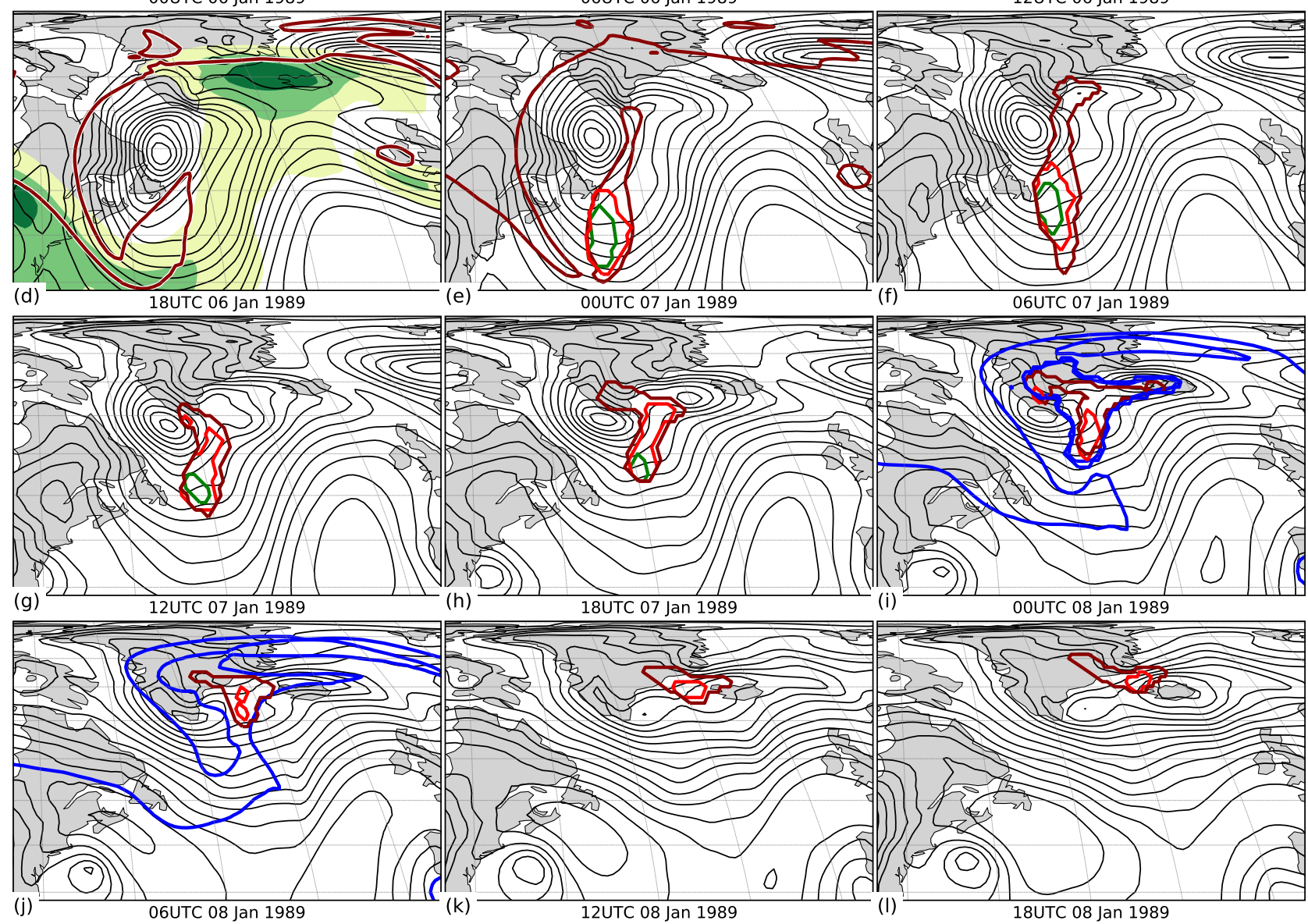

18UTC 07 Jan 1989
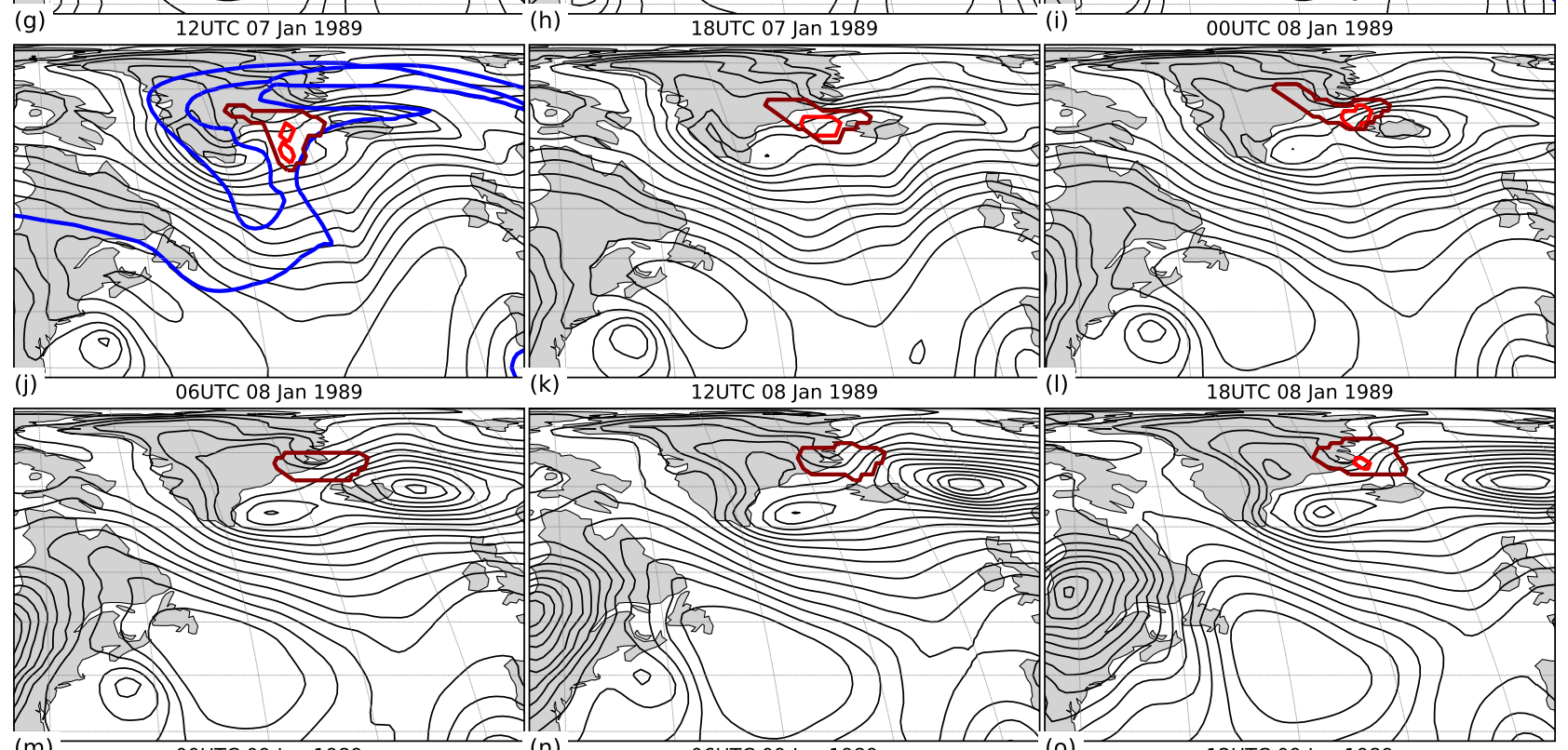

(k) $\frac{(-1989}{12 U T C ~ 08 ~ J a n ~} 1989$
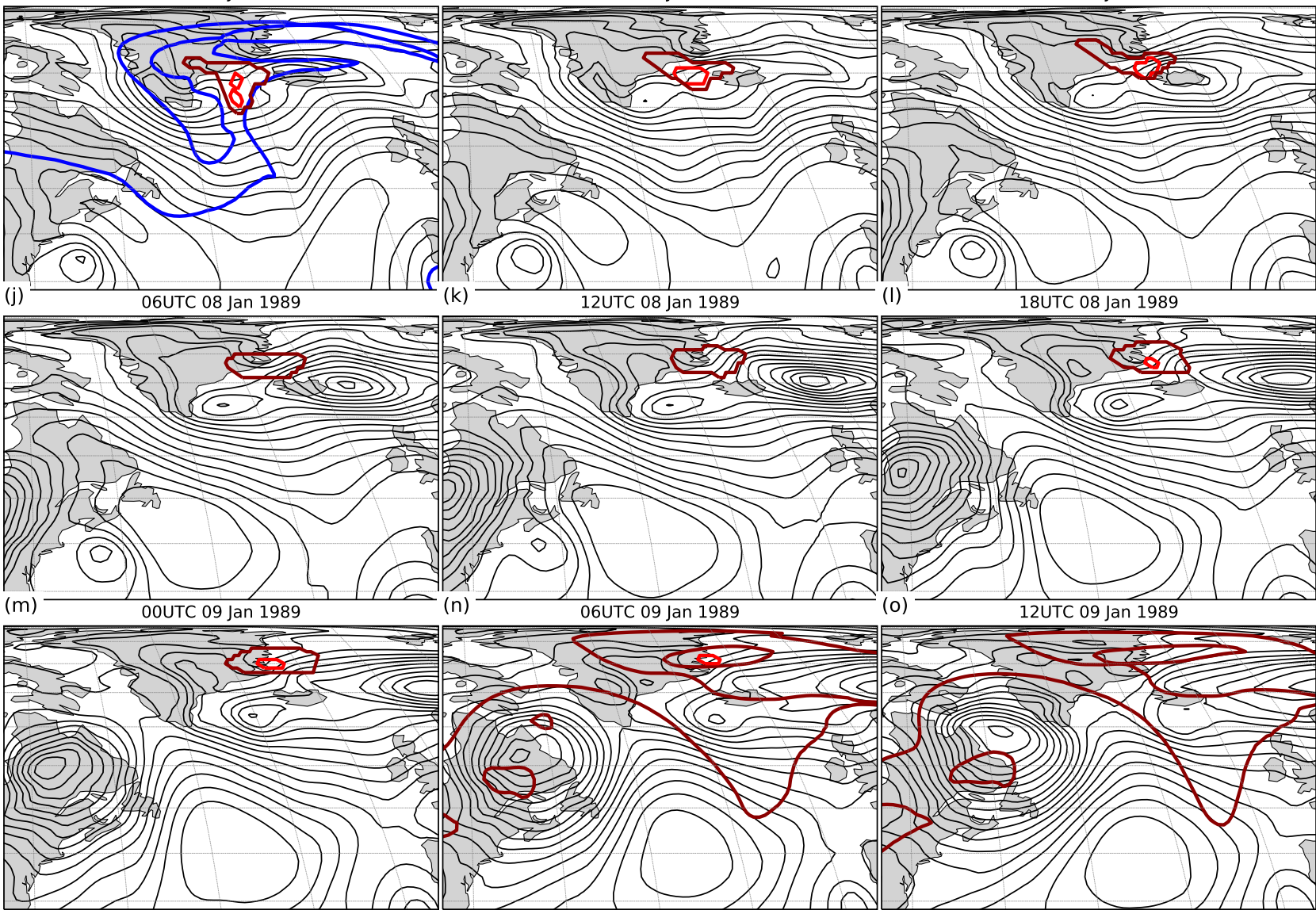

Figure S 4. Case study of a PV cutoff forming over the western North Atlantic (Type III, cyclonic). Shown are the 2 PVU isoline on (a,b,n,o) $300 \mathrm{~K}$ (brown) and on (f,g) $305 \mathrm{~K}$ and masks of the identified PV cutoff at $290 \mathrm{~K}$ (green), $295 \mathrm{~K}$ (red), $300 \mathrm{~K}$ (brown), and $305 \mathrm{~K}$ (blue), sea level pressure (black), and, for panel (a), wind speed at $250 \mathrm{hPa}$ (green shading, 20,40,60 $\mathrm{m} \mathrm{s}^{-1}$ ). 